\title{
Guest Editorial: Consciousness and Substance: The Primal Forms of God
}

\author{
John White, M.A.T. \\ Cheshire, Connecticut
}

There is a widespread notion among New Age-oriented people and spiritual seekers that consciousness is energy, and that working with energy will per se change one's consciousness and bring enlightenment. This is a fallacy, and a spiritually dangerous one at that. States of consciousness can be correlated with states of energy, but they cannot be equated.

Consciousness is wholly outside the realm of matter and energy, although at the same time it is coextensive with the whole of it. As the American spiritual teacher Da Love-Ananda (formerly Da Free, John) put it in The Hymn of the Master (Da Free John, 1982): "I AM smaller than the atom. I AM larger than the universe" (Verse 97). Consciousness is omnipresent throughout manifest creation as a universal field, yet it is not inherently a property of any part of that creation. As is classically (and paradoxically) said about enlightenment, consciousness is that which is totally involved with, yet totally unattached to, the realm of nature and phenomena. In other words, consciousness is uncreated. It wholly transcends the cosmos, including substance in all its forms, from the most solid matter to the most subtle energy radiations and etheric/celestial vibrations. Consciousness permeates or bathes all creation. In Da Love-Ananda's terms, everything resides or inheres in consciousness. But consciousness was present before cre-

John White, M.A.T., formerly Director of Education for the Institute of Noetic Sciences and President of Alpha Logics, is currently engaged in independent writing, editing, and lecturing in parascience, consciousness research, and higher human development. Requests for reprints should be sent to Mr. White at 60 Pound Ridge Road, Cheshire, CT 06410 . 
tion itself and, in that far distant future when the cosmos is annihilated and withdrawn into the unmanifest state of God, consciousness will remain.

That is not to say that God is consciousness alone. God includes consciousness-God includes everything-but God cannot be defined as anything, even consciousness. To define is to delimit. But God is unlimited, infinite, and infinitely beyond definition or description. God is ultimately mysterious, beyond all human attempts to encompass in words and thoughts and intellectual formulas. God cannot be comprehended, only apprehended.

But in our apprehension of the Ultimate Mystery, we can nevertheless say that the two primal aspects of God are consciousness and substance (or matter/energy). In the terminology of Da Love-Ananda, God, or the Transcendental Domain that enfolds all creation, issues forth into creation as the Radiant Transcendental Consciousness and the Radiant Life-Current. All objects, entities, and organisms in the cosmos, all planes of being and forms of experience, result from combinations and permutations of these aspects of God. They are the poles of existence from which humanity begins, although it begins in the sleep of ignorance/nescience, and to which humanity is called to awaken, in knowledge/conscience and realization of reality. They are the poles to which evolving humanity must align and yield itself in radical understanding, transcending all sense of separateness and independence.

Consciousness and substance are the two primal aspects of Being or God to which we must release our attention and open our body/minds in profound conductivity if we are to fulfill our destiny and become enlightened. To identify only with one or the other is to assume a stance in the world that is incomplete, unfulfilled, and therefore unhappy. The person whose sense of self is thus identified or posited is forever seeking, yet perpetually self-defeated by the implicitly drawn boundary in his or her consciousness that divides existence into self and nonself, inner and outer, subject and object. Duality and universal opposites characterize such a person's perception of reality. It is a most bleak, absurd, and sour (dukkha, as the Buddha put it) existence.

Baruch Spinoza remarked that matter is God as extension. That is true, but it would be more accurate to say that substance (that is, both matter and energy) is God as extension. However, even the totality of the universe does not define God; that would be simply pantheism. To complete the picture of manifest creation, we must say that if substance is God as extension, consciousness is God as intention. Will, volition, purpose, meaning, motivation - these are aspects of ourselves that can never be explained in electrochemical terms, astrophysical 
terms, or anything whatsoever that is matter/energy in the realm of nature. Thus, consciousness and substance are the subjective and objective aspects of God. They are, in theological terms, the traditional aspects of God as imminent and omnipresent. Although this doesn't define God either, for there is the transcendent unmanifest aspect of God that is entirely beyond the universe, it is more accurate and comprehensive than Spinoza's remark, and has been called panentheism by Alfred North Whitehead. To use the phrasing of Da LoveAnanda, God or the Transcendent Being is the Identity or Subject of all selves or subjects, and the Condition or Objective source of all notselves or objects.

We see this situation reflected in miniature in ourselves. We are both subject and object. We are creatures, but we are also aware of ourselves as creatures. We can say, "I have a body, but I am not my body; I have a mind, but I am not my mind." We are not merely a body/mind, however complex and subtle it appears. Our true identity transcends the entire body/mind complex. So we can also say that consciousness is selfcreated, but that creative self is not our egoic body/mind self. Rather, it is the Self of all, which is a traditional term for God, the Supreme Identity, the Radiant Transcendental Being who is the One-in-all.

Consciousness and substance coexist and interact universally, and thus consciousness is present in the most rudimentary forms of energy and matter, even subatomic particles. Nevertheless, for theoretical purposes of understanding, it is necessary to distinguish consciousness from energy/matter. Otherwise, we run the risk of thinking that generating energetic effects in our bodies or in the environment is the same thing as changing consciousness.

Some spiritual seekers, failing to understand this distinction, become "energy junkies." They learn with fine detail how to manipulate energy inside themselves or attract energy to themselves from outside. They may generate effects in the body/mind that are often very dramatic, even overwhelming. They may, for example, experience great bursts of internal light, ecstatic mind-states, loss of body awareness, blissful celestial sounds, skyrides of unearthly colors, and so forth. Yet when the experience is over, their consciousness has not changed a whit. They don't understand what occurred, nor do they seem to care to radically understand. After the internal pyrotechnics have subsided, it is consciousness alone that can bring understanding to the person. Without that reflection upon experience, without self-awareness of what it is that can observe experience or energy at all, they are not mystical-they are merely mystified. Their ego is still the dominant focus of awareness, and the only effect of the experience is to sharpen 
their desire for still more experience, through drugs, sex, or other energy-arousing situations, including certain meditative practices that are not true or real meditation, rather than getting rid of the experiencer-that is, the egocentric state of consciousness that seeks experience for personal gain, rather than resting freely in God, the Source of all experience, the Condition of all conditions.

Ask yourself: What is "reflection upon experience?" It is essentially transcendence of experience. It is disengagement and disidentification from the experience in all its subjectivity, so that understanding is gained through objectivity. Psychologically speaking, for liberation to occur, the entire universe must ultimately become an object of consciousness. Only when the cosmos, the entire realm of nature and phenomena, is transcended in consciousness, can there be enlightenment. Yet in that moment of objective clarity and transcendence of all creation is the paradoxical discovery that one's true being includes all that is transcended. Transcendence is not mere negation. That is why enlightenment is described as that condition of consciousness that is totally involved in the universe, yet also totally detached from the universe. Thus arises the yogic ideal of nonattachment, nonaversion: perfect equanimity.

Energetic effects may accompany changes in consciousness, and often do, but they are not at all necessary. Energy junkies don't understand that it is their own consciousness that first of all directs them toward an experience, prior to all manifestations of energy, and that then imposes itself upon energy to create the experience sought. They don't understand that it is only because we are first of all conscious of our energies that we can work intelligently with and through our energies.

Furthermore, energy junkies compound their basic mistake of thinking that energy equals consciousness by then saying that there are two forms of energy, positive and negative, or masculine and feminine, with which to work. This is more nonsense. There is no such thing as positive and negative energy or masculine and feminine energy; there is only energy, period. The perceived duality of energy is a reflection of the mind perceiving the energy, not the energy itself. As Zen puts it: to the pure in heart, all things are pure. There are positive and negative effects, but those effects are a function of how the energy is applied or experienced, and it is always consciousness that applies or directs or experiences energy in all its forms. The mind interprets things as positive or negative, according to its understanding, which is to say, according to its level of consciousness, but the energy itself remains undivided, seamless as the universe itself. 
There is an enormous amount of nonsense about energy, which leads people to become energy junkies, all because of the mistaken notion that consciousness and energy are the same thing. But they are not. Even healing, one of the best uses of energy, does not necessarily change consciousness in the person being healed. Consider the story of Jesus cleansing the ten lepers (Luke 17:11-19). Only one of them responded spiritually to Jesus's use of energy, because that one alone reflected in consciousness upon his experience. The other nine went their way without the least thought of expressing thanks to Jesus. Their awareness was not changed by the healing energy; it remained egoic, self-centered, bound.

The eye does not see itself, and energy does not direct itself. It is always subject to direction and control by a senior influence. That influence is consciousness. There is nothing, absolutely nothing, that can be done with energy in and of itself to change consciousness. Enlightenment is not possible in any way whatsoever through the manipulation of energy, no matter how subtle or ethereal the energy, no matter how celestially vast the field of energy. All that does is produce phenomena, whereas enlightenment is transcendence of all phenomena. All that does is produce illusion and hallucination, whereas enlightenment is the clear perception of reality through release of attention from all partial states and from all identification with phenomena. Transcendence does not deny or reject partial states, nor does it reject or deny phenomena. Transcendence simply sees them in perspective, as less than infinite and ultimate, so that attention rests freely in its source-condition, which is unbound consciousness, consciousness that does not recoil from infinity. That infinite consciousness is your primal identity, beyond all partial circumstances and conditional phenomena. And it is none other than God.

There is an incredible amount of energy-oriented nonsense occurring today in the name of higher consciousness. The frenzied search that energy junkies make for this or that "energy high" is-I have to say it-pathetic. It is sadly ironic that their glamorous, alluring notions about energy as the key to spiritual growth are precisely what prevents their own enlightenment. Some people urge you to wear crystals or gemstones to "cleanse and balance your aura" for spiritual growth. Others solemnly declare that you must meditate at rare "power points" on the planet or else sit inside a pyramid or other geometric form so you can "receive the positive energies." Still others say you cannot gain higher consciousness unless you receive an initiation from a guru who will transfer vital force to you, so that your chakras are opened and your kundalini energy is awakened. And the psychotechnologies they 
devise are endless: meditation hats, enlightenment meters, high-tech flotation tanks, astral sound recordings, cosmic stress alert monitors, golden brainfood algae pills, superionized vitamin XYZ, biotibetanalphafeedback tea-you name it and someone will sell you a dozen, wholesale. But it is all, all, the work of ego, and it leads nowhere except to addiction, compulsion, seeking, and suffering.

So long as something is seen or conceived or experienced as an object of consciousness, as a content of consciousness, it is still only partial, less than the infinite, ultimate wholeness that is consciousness itself. The yogic "sword of discrimination" recognized long ago that consciousness or chitshakti must be distinguished from energy or pranashakti. The latter is the content of consciousness, or that which is perceived. Chitshakti is consciousness itself, or that which perceives. It is essentially the same distinction as the paired Sanskrit terms, Purusha (spirit, self) and Prakriti (matter). Enlightenment is the condition that understands their difference in the manifest universe, and their ultimate unity at the Source of both, the perfect poise of Being-amidbecoming. Enlightenment is the condition of being aware of the universe as the universe, being cosmically conscious. It is the realization of the union of opposites, of Shiva/consciousness and Shakti/energy, of nirvana and samsara, and the transcendence of all separateness and all boundaries in the extraordinary, yet perfectly ordinary, experience of the cosmos being conscious of itself through an individual. And that is our condition, our matrix, our identity, prior to all separation, division, and differentiation. There is only God.

\section{References}

Da Free John (1982). The hymn of the master. San Rafael, CA: Dawn Horse Press. 